\title{
Monckeberg Arteriosclerosis
}

National Cancer Institute

\section{Source}

National Cancer Institute. Monckeberg Arteriosclerosis. NCI Thesaurus. Code C35770.

A type of arteriosclerosis in which calcification of the tunica media is the predominant feature. 